\title{
Flexibility or Ethical Dilemma: An Overview of the Work from Home policy in modern organizations around the world
}

\begin{abstract}
Purpose: The primary purpose of this paper is to highlight the pros and cons associated with working from home policies, and how these policies differ across countries and cultures.

Design/Methodology/Approach: Opinions of practitioners and examples of some leading controversial working from home policies have been discussed in detail.

Findings: Culture has a significant impact on the flexible work arrangement policies. Although many companies endorse some degree of flexibility for employees, companies with a control-oriented culture still struggle with working from home.
\end{abstract}

Originality Value: All the discussions and views expressed solely belong to the authors.

Paper Type: Viewpoint

Keywords: Flexible Work Arrangements, Work-Life Balance, Result Oriented

The ability to hire, develop and then retain talent is regarded as a competitive advantage for any company. Organizations are coming up with diversified compensation packages, benefits and incentives to induce loyalty and commitment amongst their workforce.

Given the dynamic environment, more and more professionals today look for a better work-life balance. Therefore, they are attracted towards the employers who can adopt flexible policies and realize that this perk is now becoming a priority for employment. This is an ideal arrangement for employees as they get a chance to remain in the workforce and continue to be employed by an established company, and also enjoy all the advantages of being at home. Due to the economic conditions, environmental factors and availability of smarter technology, 'work from home' options are quickly gaining popularity. According to International Data Corporation (IDC), the mobile worker population in United States will grow at a steady rate over the next five years, increasing from 96.2 million in 2015 to 105.4 million in 2020. It is expected that by 2020, the mobile workforce will constitute $72.3 \%$ of the total workforce (International data center, 2015). In another study, IDC found that in 2015 at United States, there are two million home based businesses and more than three million corporate home office households (Gretchen, 2011). However, as this option becomes more popular, we begin to realize that everything 
glitters is not gold. There are certain pitfalls associated with the 'work-from home policy'. Work

\section{from Home Policy: A Catalyst for increasing worker's productivity}

Companies which advocate in its favor state that the productivity level of their employees increases once they are given this facility. As far as employees are concerned, they do not have to be worried about the morning traffic jams, they can spend more time with their families, they are away from the stressful office environment and above all they are at their creative best. For organizations, this policy has somehow enabled them to hire the top talent with no geographic limits, it has even allowed companies to 'steal away' talent from their competitors, save the operational expenses and most importantly provide the much needed 'work-life balance' to their employees. The general benefits associated with this policy are:

i. Feeling of a flexible environment in which you get to decide your own working hours;

ii. Less distractions and stress, for example, professional conflicts etc ;

iii. Proximity to home and family members;

iv. Better health and better work life balance;

v. Incubation may result in greater productivity and creativity.

\section{Work from Home Policy: A compromise between speed and quality of work}

On the other hand, the critics of this policy also have some valid arguments as they claim that employees, who work remotely, are 'actually not working'(Bloom, 2014). Primarily, this argument stems from the traditional managerial mindset which fears 'the loss of control' i.e. the productivity of employees cannot be measured if they are not in direct sight. A major example in this regard was the change of work from policy at Yahoo!, when CEO Marrisa Mayer decided to relocate employees working from home to different Yahoo! facilities. Following points were raised in her memo sent to the employees (Smith, 2013):

- For a good workplace, communication and collaboration are important which means the employees should be working side-by-side;

- The best decisions come from the discussions in the hallway and cafeterias of the office and by meeting new people;

- Speed and quality of work are 'compromised' when working from home; 
- Being in the company does not relate only to your day to day job, but to your interactions and experiences which can only be possible once people work from offices.

Irrespective of Yahoo, there are some of the disadvantages associated with work from home, as cited by many managers and working professionals(Nytimescom,2013; Baytcom,n.d):

i. The difficulty in separating home from work;

ii. Self-imposed pressure of working endlessly ;

iii. The feeling of being alienated from company's major decisions and sometimes promotions.

But despite the above mentioned facts, this major decision of Yahoo! was met with severe criticism not only internally but also externally from the other companies and organizations. Even after 2 years of this announcement, Yahoo! still struggles to fully implement it. The Virgin Group founder Richard Branson in an interview to Bloomberg said that “....Marissa Mayer's Yahoo Work Policy is on the Wrong Side of History” (Otani, 2015) and that “... Companies should be flexible so employees can spend time with their kids"(Otani, 2015). Similarly Sheryl Sandberg, Facebook's Chief Operating Officer has also said that most companies can become more flexible than they really are, by implementing a few changes i.e. they need to be more result focused rather than face time focused. You need to measure the results, rather than watching people 'try'. There's a difference between seeming productive and being productive. Sandberg said ".... Of course we care that people tried, but when you do that, you build this culture of being seen in the office trying, which is different than results"(Otani, 2015).

\section{Effect of National Culture on Flexible Work Arrangements}

Based upon the points highlighted above, a major factor for companies considering implementing hom working is the national culture. This means a universal work from home policy is unlikely to be possible for all organizations located in any part of the world. The organizations need to revise and review their flexible work arrangement policies based upon their geographic locations. For example, in Pakistan, the Pakistan Telecommunication Authority became the first public-sector organization to announce work-from home policy for 'female workers' only on a trial basis. According to the current policy, selected female workers will be 
allowed to work from home, on just one day of the week. The results of the policy will be assessed and then a decision to continue with it or withdraw it shall be taken.

Likewise, there are certain Non-Governmental Organizations (NGO's) who offered flexible work arrangements, but withdrew their offer within six months. Some multinational organizations operating in Pakistan, offering work from home policy, have made it compulsory for the employees to be present in office at least once a week. This shows that the cultural dimensions have a significant impact on the implementation of this policy, as Pakistan ranks high on Hofstede's dimension of Power Distance (Hofstede, 2016). The typical mindset of toplevel management in Pakistani organizations, which believes that employees can only be managed and controlled if they are in sight, restrict them from implementing such policies These organizations witnessed a sharp decline in their productivity levels, there by withdrawing all such perks given to their employees. On the other hand, in western cultures or in more developed states, there are people who advocate that work from home policies should become a 'standard operating procedure' rather than a perk. A reason for that could be, that people in those cultures do realize the benefits associated with this policy or the organizations operating there are more result-oriented rather than control-oriented.

\section{Moving Forward with Work from home policies}

Working from home is not for everyone i.e. it requires a lot of dedication; self-control and discipline to understand how working from home functions. It requires effort not to get distracted and lose momentum. The issue with organizations is that they provide this facility to the employees without providing any training or even information on how this policy can benefit them. A major issue which has been observed in Pakistani organizations is that the employees who are offered this facility are not even aware of the difference between 'work from home' and 'extended vacations'. They try to fit-in their office work in between their home tasks, rather than doing otherwise.

Although many companies endorse some degree of flexibility for employees, working from home is still contested in some countries. However, the current trend indicates that in future, working from home would eventually become commonplace. It is important that as we move forward, companies realize in order to both compete and retain the best possible talent, they need 
to come up with flexible work options. But, as suggested earlier, the employees should be properly trained on how to do this effectively in order for companies and employees to make working from home work.

\section{REFERENCES}

1. Baytcom. (2015). Bayt: The Advantages and Disadvantages of Working from Home. Retrieved 03 March, 2016, from http://www.bayt.com/en/career-article-1601/

2. Bloom, N. (2014). Harvard Business Review: To Raise Productivity, Let More Employees Work from Home. Retrieved 03 March, 2016, from https://hbr.org/2014/01/to-raise-productivity-letmore-employees-work-from-home

3. Gretchen , M. (2011). Travel Agent Central - Home-Based Businesses on the Rise. Retrieved 06 March, 2016, from http://www.travelagentcentral.com/home-based/trends-research/home-basedbusinesses-rise-27450

4. Hofstede, G. (2016). The Hofstede Center: Country Comparison- Pakistan . Retrieved 20 March, 2016, from http://geert-hofstede.com/pakistan.html

5. International data center . (2015). IDC Forecasts US Mobile Worker Population to Surpass 105 Million by 2020 . Retrieved 05 March, 2016, from https://www.idc.com/getdoc.jsp?containerId=prUS25705415

6. Nytimescom. (2013). NY Times Sunday Review Editorial: Location, Location, Location. Retrieved $02 \quad$ March, 2016, from http://www.nytimes.com/2013/03/03/opinion/sunday/working-from-home-vs-theoffice.html? $\mathrm{r}=0$

7. Otani, A. (2015). Bloomberg Business: Richard Branson - Marissa Mayer's Yahoo Work Policy Is on the Wrong Side of History. Retrieved 06 March, 2016, from http://www.bloomberg.com/news/articles/2015-04-24/richard-branson-marissa-mayer-s-yahoowork-policy-is-on-the-wrong-side-of-history

8. Smith, K. (2013). Business Insider: Here's The Confidential Memo Yahoo Sent Employees About Working From Home. Retrieved 06 March, 2016, from http://www.businessinsider.com/yahooworking-from-home-memo-2013-2 